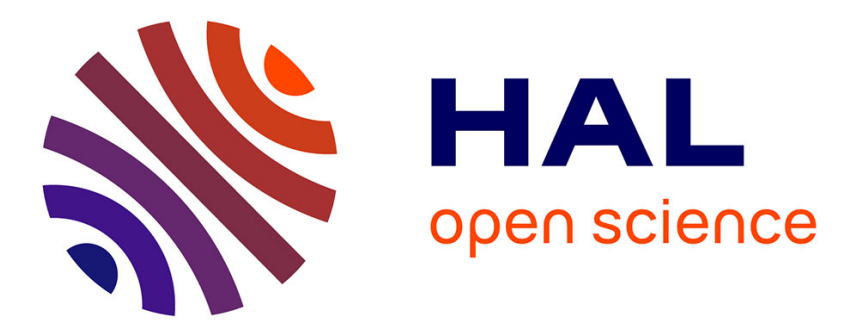

\title{
Numerical study of defects in glass reinforced composite transducer shells
}

\author{
J.-C. Debus, B. Hamonic
}

\section{To cite this version:}

J.-C. Debus, B. Hamonic. Numerical study of defects in glass reinforced composite transducer shells. Journal de Physique IV Proceedings, 1994, 04 (C5), pp.C5-347-C5-350. 10.1051/jp4:1994572 . jpa00253067

\section{HAL Id: jpa-00253067 https://hal.science/jpa-00253067}

Submitted on 1 Jan 1994

HAL is a multi-disciplinary open access archive for the deposit and dissemination of scientific research documents, whether they are published or not. The documents may come from teaching and research institutions in France or abroad, or from public or private research centers.
L'archive ouverte pluridisciplinaire HAL, est destinée au dépôt et à la diffusion de documents scientifiques de niveau recherche, publiés ou non, émanant des établissements d'enseignement et de recherche français ou étrangers, des laboratoires publics ou privés. 


\title{
Numerical study of defects in glass reinforced composite transducer shells
}

\author{
J.-C. DEBUS and B. HAMONIC
}

IEMN, Département ISEN, 41 Boulevard Vauban, 59046 Lille cedex, France

\begin{abstract}
Résumé : Les problèmes de fatigue dans les coques en matériaux composites des transducteurs flextensionnels peuvent être étudiés soit expérimentalement soit numériquement. Malheureusement, dans le premier cas les résultats sont difficilement transposables à la réalité. Dans le deuxième cas une modélisation simple permet rarement de décrire les problèmes de fatigue et de fissure dans la structure réelle. L'approche proposée ici consiste à utiliser la modification de la réponse modale de la coque pour identifier de façon qualitative et quantitative les différents problèmes survenant en service. Cet article présente dans un premier temps les éléments composites nécessaires à la modélisation du problème. Dans un deuxième temps, l'approche est validée sur un exemple de coque. Dans un troisième temps les résultats comparatifs de l'étude numérique et de l'étude expérimentale de l'endommagement d'une plaque composite sont exposés.
\end{abstract}

Abstract: Fatigue in composite shells of flextensional transducers can be investigated experimentally but in service results transposition is uncertain. This study can also be carried out numerically. However, a simple model rarely allows to describe the fracture in fatigue of an existing structure. The approach that is suggested here aims (starting from a modal analysis of a damaged structure in situ and according to results of a numerical computation by finite elements) at identifying the type of flaw in a qualitative and quantitative way. This paper first presents the finite element used to deal with this problem. Second the approach is validated on a shell example. Finally an experiment on a simple G.R.P. plate is used to compare numerical and experimental results to validate the approach.

\section{INTRODUCTION}

A class IV flextensional transducer is built with a cylindrical outer shell, whose cross-section is generally convex and oval, flat-oval or elliptical, but can also be concave (1-2). Inside the shell and in its midplane, piezoelectric or magnetostrictive longitudinal motors are tightly inserted, parallel to the shell major axis and regularly spaced. Under an electrical drive, these motors undergo a longitudinal vibration which is transmitted to the shell and converted into a flexural motion, with a large mechanical amplification. With respect to class IV flextensional transducer design, the shell is a critical element. First projectors were built with relatively thin shells, but present designs generally rely upon the use of thick shells that ensure a better electromechanical coupling for the whole structure as well as a larger bandwidth and a greater depth capability. Moreover, metallic shells have often been used, particularly aluminum shells but, today, glass reinforced plastic (GRP) shells are very often used because they allow, all the other parameters being unchanged, a reduced resonance frequency and weight as well as an increase in the 
bandwidth. One of the problem that can occur with composite shell is a fatigue damage corresponding to the initiation of growth of microcracks which propagate under the effect of cyclic loading and which generally coalesce, causing first macrocracks then failure of the structure. In composite materials there are three main types of defects whatever the number of cycles: fractures of the matrix along the fibers in plies not aligned with the applied load, which is the transverse cracking phenomenon; delamination between plies; fiber fracture, occurring mainly at the end of the structure life.

It has been the aim of this work first to use specific finite elements which are devoted to the description of the composite dynamic behavior to study the influence of the defects on the resonance frequency of some probe in order to know if it is possible to do in service monitoring of flextensional transducers using the frequency variation caused by the fatigue damage of the shell. This paper present a validation of the approach on simple composite probe starting from analytical solutions or modal analysis of a damaged shell and comparing to results of a numerical computation by finite elements. A simple G.R.P. plate is then used to compare numerical and experimental results. Even if the three main type of defect have been studied, fiber fracture will only be addressed here.

\section{FINITE ELEMENT MODELING OF A COMPOSITE SHELL}

Finite element modeling of composite materials generally relies upon a macromechanical approach in which only measured or fitted averaged apparent mechanical properties are considered. However, in this case, no material adjustments are possible, though important parameters such as fiber material nature, matrix material nature, fiber volume fraction, fiber orientation, number, thickness and order of the laminae can be modified by the manufacturer. Thus, a micromechanical approach which can predict the elastic moduli of the composite material in terms of the elastic moduli of the constituent materials has been preferred here though it embodies numerous simplifying assumptions with regard to the description of the detailed interactions of the composite constituents. In this work, the Halpin and Tsai micromechanical model has been solely used due to its wide application field. The finite elements used here (3) are made up of laminated fiber reinforced composite materials, of which GRP and CG are particular cases. This laminated composite, or laminate, consists of different layers, or laminae, which are bonded together. Each lamina is a flat or curved arrangement of unidirectional fibers embedded in a matrix, and fibers in successive laminae are differently oriented, to give different strengths and stiffness in the various directions. In the useful cases, regular angle-ply laminates are required, in which all laminae have the same thickness while fibers in successive laminae are oriented at $\pm \alpha$ degrees with respect to a reference direction. These particular laminates are symmetric or antisymmetric, depending upon the evenness of the layer number. Moreover, in the composites which are concerned, E-glass fibers or HTA carbon fibers and epoxy matrices are assumed. Nevertheless, any laminated fiber reinforced composite is likely to be modeled using these elements

To describe the mechanical properties of a laminate, basic restrictions are imposed upon the material: (i), each lamina is macroscopically homogeneous, elastic, transversely isotropic, initially stress-free, (ii), fibers are homogeneous, elastic, isotropic, aligned and regularly spaced, (iii), the matrix is homogeneous, elastic, isotropic, (iv) no voids exist in the fibers or matrix, or between them, (v) the laminate is presumed to consist of perfectly bonded laminae and (vi), the bonds are assumed to be infinitesimally thin and nonshear-deformable. Then, within a lamina and with respect to the fiber axes, the classical strain-stress relation of a transversely isotropic material holds.

\section{TESTS EXAMPLES}

\subsection{Flextensional shell analysis}

The finite element development explained in the above paragraphs was fully validated using analytical solution or experiments for all kind of fatigue problems including matrix cracking, delamination, fiber 
breakage and interfacial debonding (3). The following examples show that if the frequency variation is not too small it is possible to identify the type of flaw in a qualitative and quantitative way from a modal analysis of a damaged structure. The structure under study and the type of flow we modeled are represented in Fig. 1. Taking advantage of the symmetry of the structure only one half is modeled. Results presented in Tab 1 show that the frequency shift for some modes is significant. In this table the first letters characterize a symmetry or an antisymmetry with respect to the YOZ plane and the second letter as the same meaning with respect to the XOY plane.

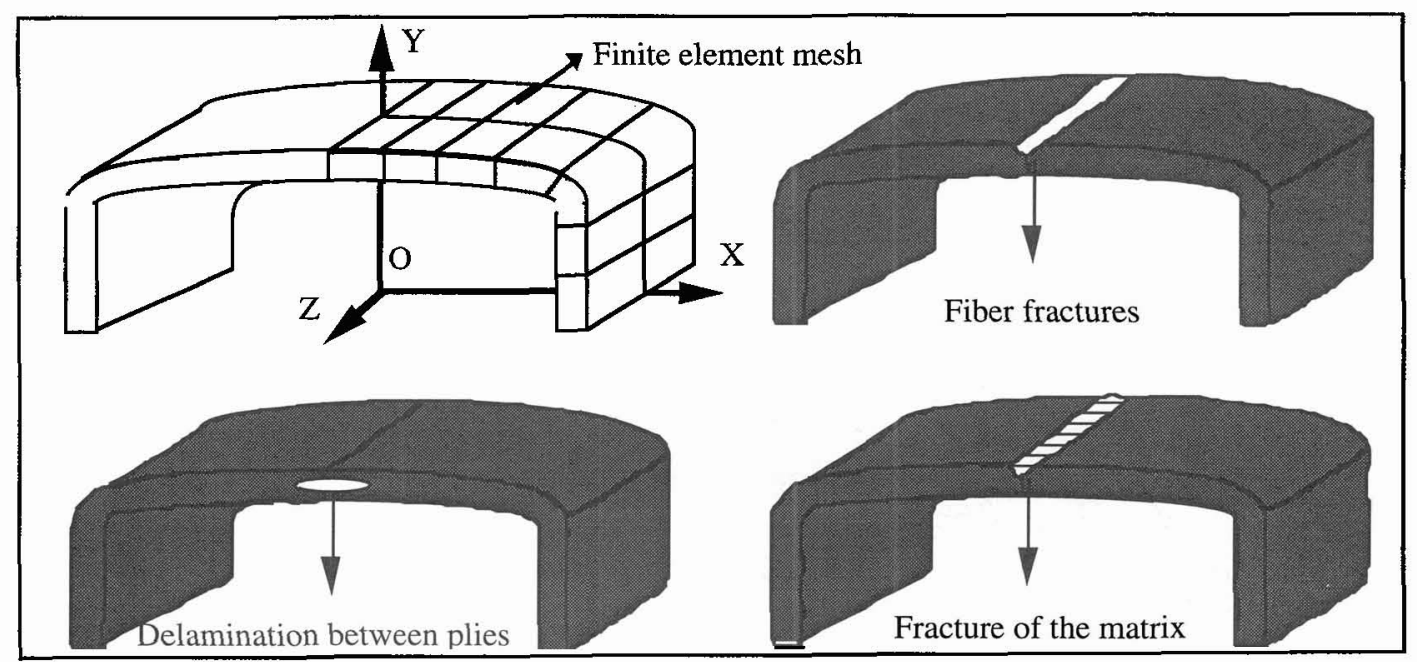

Fig. 1: G.R.P. Shell transducer and type of flow.

Tab. 1. Maximum variation of the first frequencies of a 0 oriented fiber composite shell.

\begin{tabular}{|l|c||c||c||c||c||c||c||c|}
\hline $\begin{array}{c}\text { Mode type } \\
\text { Mode failure }\end{array}$ & $\begin{array}{c}\text { AS1 } \\
\%\end{array}$ & $\begin{array}{c}\text { SS1 } \\
\%\end{array}$ & $\begin{array}{c}\text { AA1 } \\
\%\end{array}$ & $\begin{array}{c}\text { SA1 } \\
\%\end{array}$ & $\begin{array}{c}\text { SS2 } \\
\%\end{array}$ & $\begin{array}{c}\text { AS2 } \\
\%\end{array}$ & $\begin{array}{c}\text { SA2 } \\
\%\end{array}$ & $\begin{array}{c}\text { SS3 } \\
\%\end{array}$ \\
\hline Delamination & 15 & 16 & 20 & 22 & 19 & 27 & 19 & 25 \\
\hline Fiber fracture & 0 & 37 & 0 & 14 & 10 & 0 & 4 & 7 \\
\hline Matrix fracture & 0 & 15 & 0 & 5 & 4 & 0 & 2 & 3 \\
\hline
\end{tabular}

Frequency variation is mainly related to the mode shape. In the case of fiber and matrix fracture frequencies that are most affected are those of mode shape that are symmetrical with respect to the $\mathrm{X}$ axis because the damaged section is located at a maximum displacement amplitude. On the other hand mode labeled AS1, AA1, AS2 have no frequency shift because the damage section is located on a nodal line. An other study concerning the SS1 mode has been done to investigate the possibility of using this method for any kind of fiber orientation. We tried four different orientations and the results are presented in Tab. 2

Tab. 2: Maximum variation of SS1 mode

\begin{tabular}{|l|c||c||c||c|}
\hline \multicolumn{1}{|c|}{ Mode type } & $0^{\circ}$ & $30^{\circ}$ & $45^{\circ}$ & $60^{\circ}$ \\
Mode failure & $\%$ & $\%$ & $\%$ & $\%$ \\
\hline Delamination & 16 & 17 & 13 & 14 \\
\hline Fiber fracture & 37 & 30 & 25 & 24 \\
\hline Matrix fracture & 15 & 12 & 10 & 9 \\
\hline
\end{tabular}

It is interesting to notice that the frequency shift for this particular crack gives the same kind of variation and this is mainly due to the decrease in stiffness with respect to this mode. 


\subsection{Comparison with experimental results}

To get the resonant frequencies and the associated displacement field a home made experiment has been built. The principle relies on the excitation of the modes by a loud speaker. The detection of these modes was done using a simple accelerometer of low size and weight in order to keep the displacement field free. The working frequencies of the device are in the frequency range $10 \mathrm{~Hz}-40 \mathrm{kHz}$.

The structure we first study is a thin G.R.P. plate. To model the dynamic behavior of this plate we took in to account the symmetry of the structure. We used a $6 \times 12 \times 2$ mesh which gives 2700 d.o.f. (Fig. 2). We looked at the frequency variation with respect to the fiber fracture size. Results for numerical computation and experiment were similar and the frequency variation is presented in Tab. 3. A very quick analysis of the results show that the SS modes are more affected than the other for the same reason as before.

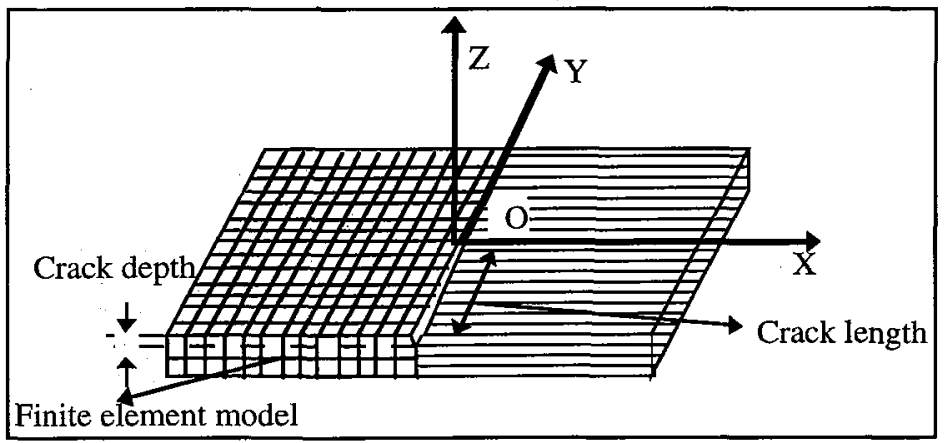

Fig. 2: G.R.P. plate for experimental study.

Tab. 3: Maximum variation of SS1 mode

\begin{tabular}{|l|c||c||c||c|}
\hline $\begin{array}{c}\text { Mode type } \\
\text { Crack size }\end{array}$ & $\begin{array}{c}\text { SS1 } \\
\%\end{array}$ & $\begin{array}{c}\text { SS3 } \\
\%\end{array}$ & $\begin{array}{c}\text { SA4 } \\
\%\end{array}$ & $\begin{array}{c}\text { SS4 } \\
\%\end{array}$ \\
\hline $200 \times 2,5 \mathrm{~mm}$ & 10 & 2 & 3 & 5 \\
\hline $200 \times 7,5 \mathrm{~mm}$ & 50 & 6 & 16 & 25 \\
\hline
\end{tabular}

\section{CONCLUSION}

This article shows that composite finite element based on a micromechanical approach can be used first to model the variation in resonance frequency due to fatigue fracture in composite shell. To improve the results of this study, other location of fracture must be investigate before using the technique for a real in service performance monitoring of composite shell flextensional transducers.

\section{REFERENCES}

[1] Marshall W.J., Pagliarini J.A and White R.P., IEEE Oceans, (1979)124-133.

[2] Bromfield G., "Class IV flextensional transducers," in Power transducers for sonics and ultrasonics, Ed. by B. Hamonic, O.B. Wilson and J.N. Decarpigny, Springer-Verlag Ed., (1991) 48-59.

[3] Ghaddar A., "Etude de la dégradation des coques en matériaux composites utilisées dans les transducteurs flextensionnels à l'aide de la méthode des éléments finis," $\mathrm{Ph} \mathrm{D}$; disssertation $\mathrm{N}^{\circ}$ 891, Lille University (1992). 